\title{
Adaptação Visando Melhora do Desempenho Funcional em Atividade da Vida Diária para Adolescente com Artrite Reumatóide Juvenil
}

\author{
Johanna Noordhoek ${ }^{(1)}$ e Fabricia Quintão Loschiavo(2)
}

A artrite reumatóide juvenil (ARJ) é a doença reumática mais comum na infância e uma significante causa de incapacidade $^{(1)}$. As restrições de membros inferiores mais comuns na ARJ incluem a perda de extensão, abdução e rotação no quadril ${ }^{(1)}$.

O objetivo da terapia ocupacional é garantir ao paciente capacidade para realizar satisfatoriamente as tarefas e funções essenciais de sua vida produtiva, assegurando-lhe o domínio de si próprio e do ambiente ${ }^{(2)}$. A intervenção terapêutica ocupacional empregada foi a abordagem da tecnologia assistiva, definida como todo o arsenal de recursos utilizados com a finalidade de proporcionar vida independente e autonomia à pessoa portadora de deficiência ${ }^{(3)}$, na execução das atividades de sua vida diária (AVD's), sejam trabalho ou lazer. Desta forma, surgiu a proposta de confecção de uma adaptação para calçar meias para uma paciente com ARJ.

S., sexo feminino, 17 anos, atendida pelo serviço de terapia ocupacional do Ambulatório Bias Fortes, do Hospital das Clínicas da Universidade Federal de Minas Gerais, apresenta uma série de limitações na amplitude de movimento em todas as articulações dos membros inferiores e superiores. De acordo com anamnese, avaliação física, e o Standford Health Assessment Questionnaire (HAQ), instrumento autoadministrável que analisa a capacidade funcional do paciente no desempenho de suas AVD's ${ }^{(4)}$, as principais incapacidades funcionais da adolescente relacionam-se com as dificuldades em suas AVD's, principalmente atividades que requeiram flexão, abdução e rotação do quadril, como, segundo demanda da paciente, calçar meias.
Visando-se então maior autonomia, independência e melhora do desempenho funcional da adolescente, por meio da simplificação do trabalho e conservação de energia ${ }^{(2)}$, surgiu a proposta de confecção de uma adaptação para este fim, com o auxílio da paciente.

A confecção do dispositivo deu-se a partir de um molde ${ }^{(5)}$. Sob a supervisão da terapeuta ocupacional, a adolescente confeccionou sua adaptação, utilizando materiais alternativos como garrafa "pet" e barbante, destacando-se assim a importância da participação da paciente no processo de desenvolvimento da adaptação.

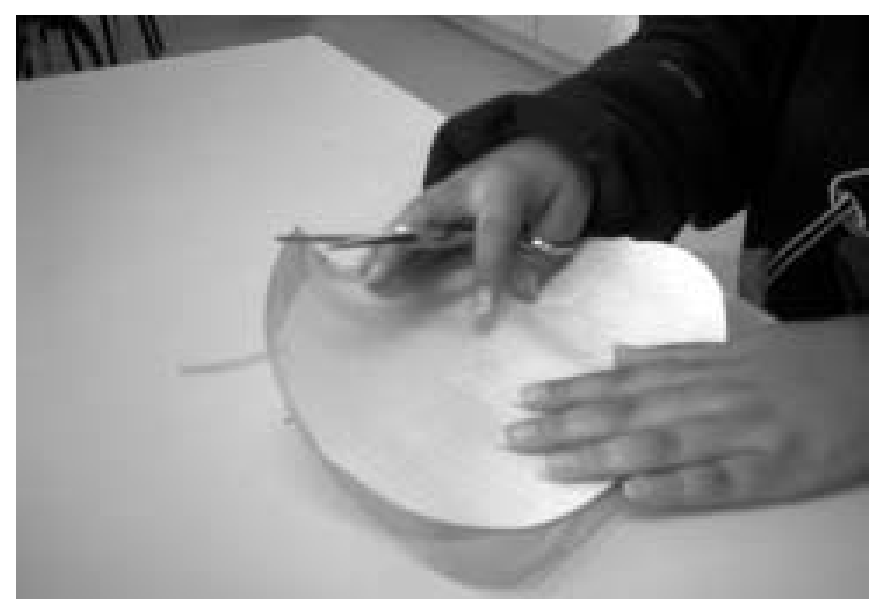

FiguRa 1 - Adolescente no processo de confecção de sua adaptação.

1. Terapeuta ocupacional, professora do Departamento de Terapia Ocupacional da Escola de Educação Física, Fisioterapia e Terapia Ocupacional da Universidade Federal de Minas Gerais (UFMG), Belo Horizonte-MG, Brasil. Coordenadora do projeto de extensão "Programa de Orientação aos Indivíduos Acometidos por Doenças Reumáticas".

2. Bolsista do projeto de extensão "Programa de Orientação aos Indivíduos com Acometidos por Doenças Reumáticas" e quintanista do curso de Terapia Ocupacional da Universidade Federal de Minas Gerais (UFMG), Belo Horizonte-MG, Brasil. 


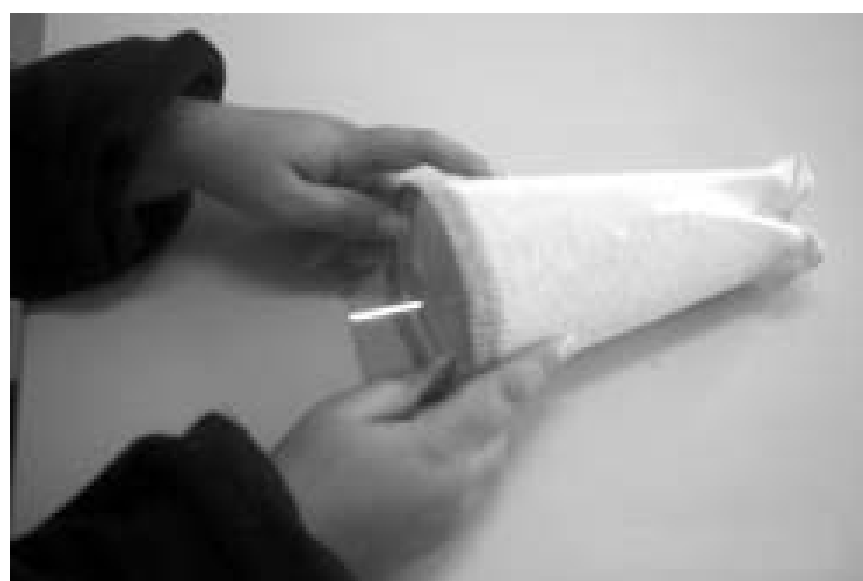

FIGURA 2 - Paciente verificando a adequação de sua adaptação ao tamanho de sua meia.

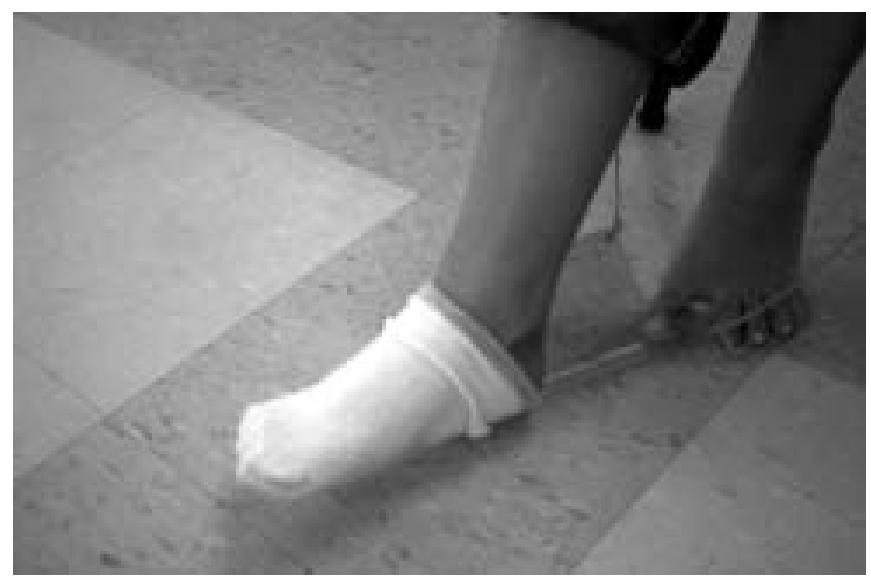

FiguRA 4 - Adolescente retirando o dispositivo.

\section{REFERÊNCIAS}

1. Klepper SE, Scull SA: Artrite Reumatóide Juvenil. In: Tecklin JS: Fisioterapia Pediátrica. Belo Horizonte, Artmed, 2002, cap12.

2. Bain BK: Tratamento dos Contextos de Desempenho. In: Neistadt ME, Crepeau EB: Terapia Ocupacional, 9.a ed, Rio de Janeiro, Guanabara Koogan, 2002, p. 438- 79, cap 21.

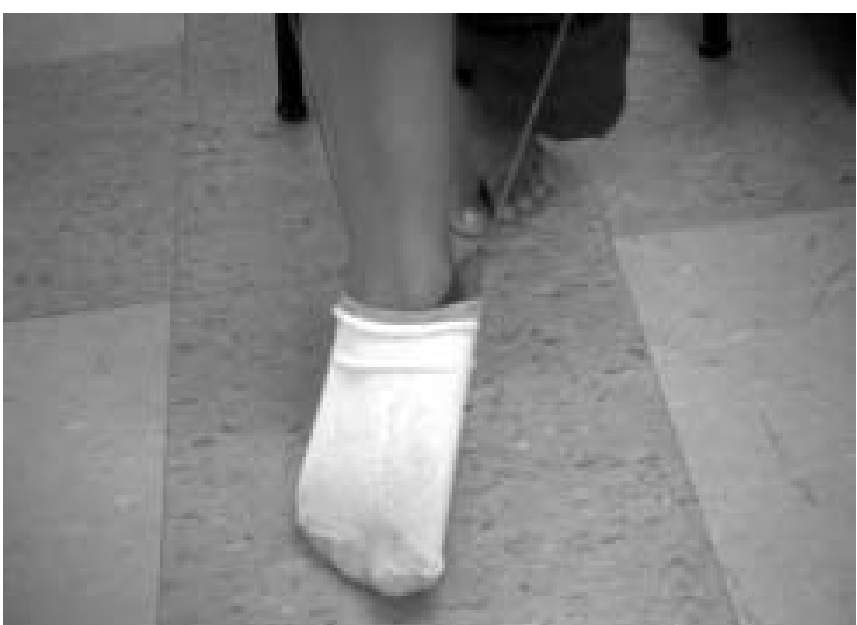

Figura 3 - Adolescente calçando a meia com auxílio da adaptação.

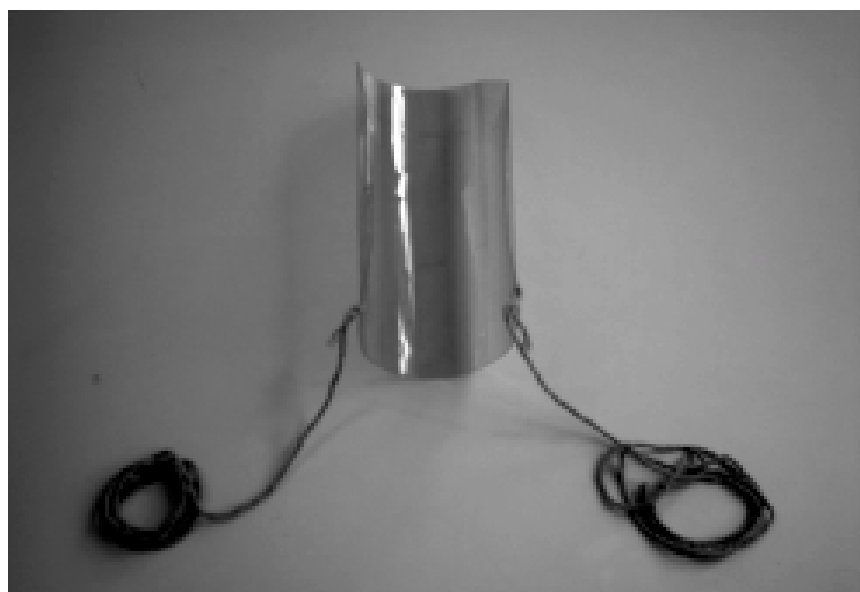

FiguRA 5 - Vista dianteira da adaptação.

3. Irene A: Tecnologia Assistiva: Abordagem Inovadora do Terapeuta Ocupacional. O Coffito 15, 2002.

4. Ciconelli RM: Medidas de Avaliação de Qualidade de Vida. Rev Bras Reumatol 43(2): IX-XIII, 2003.

5. Lorig K, Fries JF: Self-Helpers: 100+Hints and Aids. The Arthritis Helpbook, 4.a ed, New York, Perseus Book, 1995. 